\title{
Design and installation of a Prototype Geohazard Monitoring System near Machu Picchu, Peru
}

\author{
M. H. Bulmer ${ }^{1}$ and T. Farquhar ${ }^{2}$ \\ ${ }^{1}$ Geophysical Flow Observatory, Joint Center for Earth Systems Technology, University of Maryland Baltimore County, USA \\ ${ }^{2}$ Department of Mechanical Engineering, University of Maryland Baltimore County, USA
}

Received: 14 May 2010 - Revised: 25 August 2010 - Accepted: 17 September 2010 - Published: 30 September 2010

\begin{abstract}
The town of Machu Picchu, Peru, serves the $>700000$ tourists visiting Machu Picchu annually. It has grown threefold in population in the past two decades. Due to the limited low-lying ground, construction is occurring on the unstable valley slopes. Slopes range from $<10^{\circ}$ on the valley floor to $>70^{\circ}$ in the surrounding mountains. The town has grown on a delta formed at the confluence of the Alcamayo, Aguas Calientes and Vilcanota Rivers. Geohazards in and around the town of particular concern are 1) large rocks falling onto the town and/or the rail line, 2) flash flooding by any one of its three rivers, and 3) mudflows and landslides. A prototype early warning system that could monitor weather, river flow and slope stability was installed along the Aguas Calientes River in 2009. This has a distributed modular construction allowing components to be installed, maintained, salvaged, and repaired by local technicians. A diverse set of candidate power, communication and sensor technologies was evaluated. Most of the technologies had never been deployed in similar terrain, altitude or weather. The successful deployment of the prototype proved that it is technically feasible to develop early warning capacity in the town.
\end{abstract}

\section{Introduction}

Early this year, several people were killed by mudslides while hiking the famed Inka trail that leads to the citadel of Machu Picchu, Peru. Then, on 25 February 2010, torrential flooding of the Urubamba/Vilcanota River valley severed the narrow gauge rail line that has linked Machu Picchu to the outside world since the early 1900's. To minimize the risk of further casualties, the Peruvian government ordered the evac-

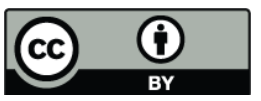

Correspondence to: $\mathrm{M}$. H. Bulmer (mbulmer@umbc.edu) uation of the 4200 tourists and residents trapped either at the World Heritage site, or in the adjacent village of Machu Picchu Pueblo (MPP), or somewhere along the Inka trail. In spite of difficult weather and terrain conditions, the ensuing airlift was successfully executed by the Peruvian Army with the assistance of the US government and other entities over a period of four days. The operation ultimately required 93 sorties by 12 turbine powered helicopters and no further injuries were sustained. However, as of early April, the Machu Picchu Sanctuary remains largely closed to tourists and the necessary repairs of the rail infrastructure are still underway. In addition to the tragic loss of human life, thousands of private residences were destroyed across the region, and 50100 commercial buildings in MPP sustained serious damage. Even as the focus shifts from humanitarian relief to economic reconstruction, the reopening of Machu Picchu to tourists should be accompanied by a clear recognition of the natural hazards of this region.

\section{Background}

For the past two years, the Geophysical Flow Group (GFG) at the University of Maryland Baltimore County has been studying the feasibility of using distributed IP-sensor arrays to monitor geohazards around MPP (Fig. 1). During an initial site evaluation in 2008 (Bulmer and Farquhar, 2008), the team concluded 1) that the risk level was very severe and 2) that the community was inadequately equipped to respond in the event of natural disasters. Hence, the impact of the recent flood was not unexpected and the safe evacuation of several thousand people highlighted that the military was the organization most able to respond. The significance of this is that the civil agencies the GFG worked with did not want to engage with the military. This exposes the need for significant

Published by Copernicus Publications on behalf of the European Geosciences Union. 


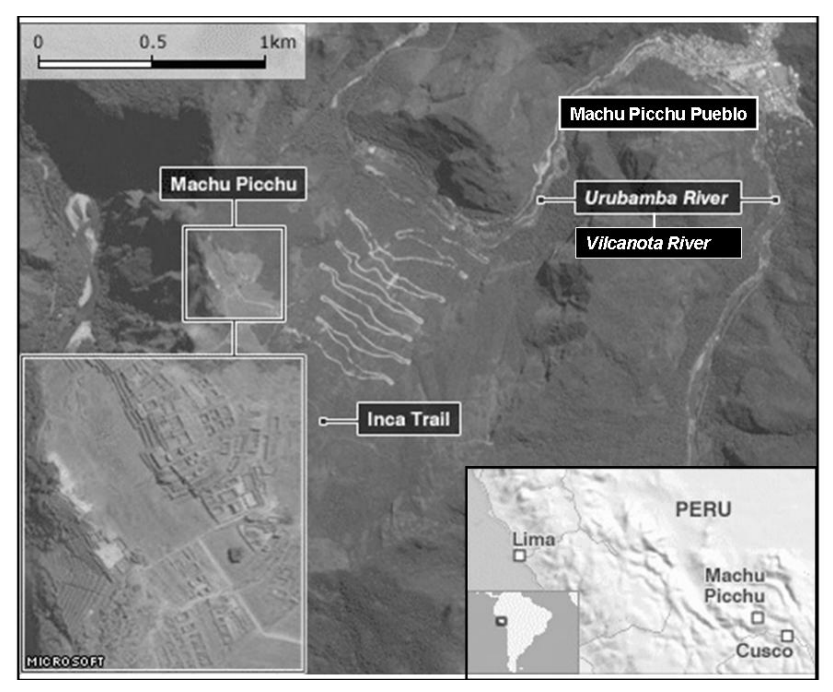

Fig. 1. Location map showing Machu Picchu and Machu Picchu Pueblo. Modified from news.bbc.co.uk.

consideration to be given to civil military cooperation not just in disaster response but in the monitoring of geohazards.

The purpose of this article is to describe a prototype early warning system designed and temporarily deployed by the GFG team in 2009 under the auspices of the World Bank. The goal here is to identify the factors that informed the system design, and to enumerate some of the key lessons learned during its installation and a subsequent four months of operation. It should also be noted that the prototype was no longer in operation at the time of the recent flood, which had been foreshadowed by an extended period of unusually heavy rain.

Most of the 1 million tourists who visit the Machu Picchu Sanctuary on an annual basis arrive by rail and make use of European-style hotels and restaurants operated by permanent residents of MPP or the nearby village of Santa Theresa. Thus, at any one time, there can be as many as 6000 people confined to the area immediately surrounding the conflux of three rivers in MPP. The natural beauty of the surrounding mountains had drawn the Inka leaders to Machu Picchu in the 1500 's just before the arrival of the Spanish Conquistadores. Then as now, the steep dynamic slopes posed a real and constant danger to any inhabitants of the valley floor. Thus, the explosive growth in tourist traffic at this World Heritage site has provided a strong impetus for early detection of geohazards, and for effective emergency planning. Towards that aim, this paper describes the design and installation of a prototype warning system ultimately installed along the lower reaches of one of the three rivers draining through MPP. The guiding principle in its design was to obtain a robust system that could be operated, maintained, and extended in a sustainable fashion under local conditions.

\section{Machu Picchu Pueblo}

MPP is situated within the Cordillera Oriental (Eastern Cordillera) between the High Plateau and Subandine zones of the Peruvian Andes (Marocco, 1977). The latitude is $13^{\circ} 09^{\prime} 25.3^{\prime \prime} \mathrm{S}$, the longitude is $72^{\circ} 31^{\prime} 25.8^{\prime \prime} \mathrm{E}$, and the mean elevation is slightly less than $2100 \mathrm{~m}$ a.s.l. The official boundaries of the town of MPP enclose a $40 \mathrm{~km}^{2}$ area of the complex Vilcabamba Batholith. This 250-million-year-old intrusion is a coarse white to gray-colored granite, characterized by an abundance of quartz, feldspar, and mica (predominantly biotite). The town has grown on a metastable delta that lies on the downstream right bank of the Vilcanota River at its confluence with the Aguas Calientes (AC) and the Alcamayo (Am) Rivers. At this location, some of the surrounding peaks rise to well over $4000 \mathrm{~m}$ at slope gradients of up to $>70^{\circ}$. MPP lies at $\mathrm{km} 122$ of a rail line which is linked to Ollantaytambo ( $\mathrm{km} 88)$ and ultimately Cusco $(\mathrm{km} 0)$ via a single narrow gauge rail track that runs along the banks of the Urubamba (or Vilcanota) River. The passenger train station in MPP serves as a rail terminus for most of the tourists who visit Machu Picchu citadel annually via a dedicated bus fleet. In recent years, the lodging capacity of MPP has grown dramatically by a factor of three to support the demands of the tourist industry. Most of the flat low-lying ground adjacent to the Vilcanota River is now occupied by large commercial buildings (e.g., major hotels and restaurants). Here, building construction reflects a general awareness of the risk of flooding with most key business activity occurring on the first floor. In contrast, most private residences and small commercial buildings are sited along the steeply sloping banks of the $\mathrm{AC}$ and the Am. Here, construction and siting practices are informal (Fig. 2), and there is a constant risk from rockfalls and other types of landslides.

The climate at MPP is subtropical, with the driest months of the winter season from May to August and the wettest months of the summer season from October to March (Fig. 3). The rainy months typically account for $80 \%$ of the annual rainfall average, which over the last two decades has averaged 1600 to $2300 \mathrm{~mm}$. The average humidity is $77 \%$ during dry months and $91 \%$ during rainy months. At any given altitude, the variations in daily temperature are modest, and frost does not occur within the boundaries of MPP.

\section{Preliminary investigation of geohazards}

Weathered and heavily fractured granitic rocks around MPP are prone to rockfalls, topples and slides. Some of the slopes are heavily vegetated but the slope gradients are sufficiently steep that the colluvium can be mobilized by intense rainfall. In other cases, the bedrock has been fully exposed and is now heavily jointed. Slope failures are frequent and reportedly are most common in the last months of the wet season (i.e. in March and April). Many of the slopes should be considered 


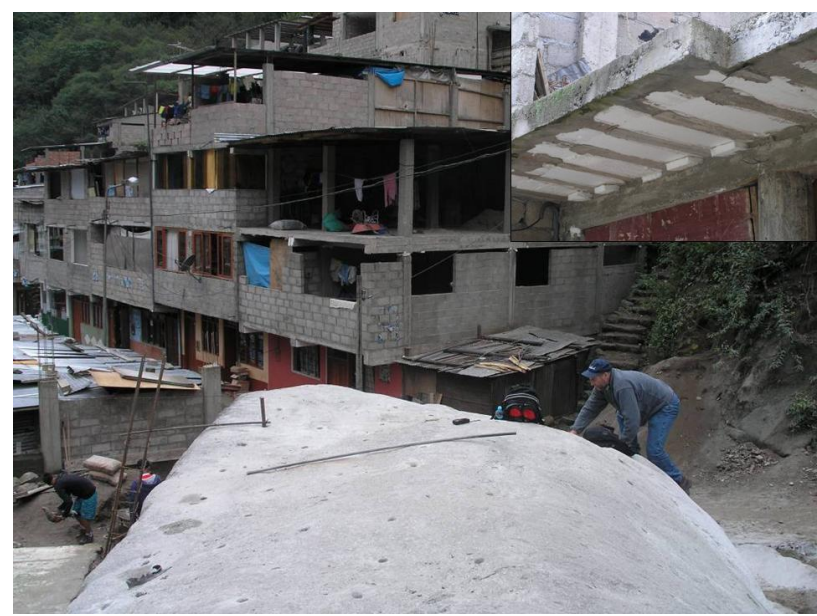

Fig. 2. Construction and siting practices are informal. A typical view of multistoried houses under construction. The basic plan is a concrete slab and reinforced column structure with no load bearing walls. The ground floor often contains a shop with several floors above for family use. Inset. View of a cantilevered floor showing the non uniform consistency of the concrete and the Styrofoam boards used as space fillers.

highly susceptible to disturbance. In the opinion of the authors, more than $70 \%$ of the inhabitants of MPP live on or just beneath meta-stable slopes, and are continually exposed to the risk of large-scale slope failure (Fig. 4).

The Aquas Calientes (AC) River runs through MPP to the Vilcanota River and has a catchment area of $\sim 1400$ hectares (Fig. 5). During periods of intense rain, the runoff rapidly drains through and over the colluvium and/or heavily jointed bedrock that comprise the narrow steep valley sides. Historical records dating to the 1940's suggest that rockfalls, topples, and debris slides into the upper tributaries of the AC occur on a regular basis. On occasion, these failed materials have dammed one or more of the upper channels of the $\mathrm{AC}$, temporarily reducing the flow volume in the lower channel, until such time as the accumulated water is suddenly released in a catastrophic manner as hyper-concentrated water flow, debris flow and/or mudflow. The Quechua word for this type of phenomenon is "huayco", which is understood to describe a broad spectrum of flows either confined within or outside of normal drainage channels. At present, the last $1000 \mathrm{~m}$ of the AC is confined by the walls of an engineered concrete channel that bisects the western side of MPP (Fig. 6). Some portions of the channel have been periodically revised and strengthened to resist the effects of previous "huaycos".

The mouth of the Alcamayo (Am) River lies only $200 \mathrm{~m}$ further upstream on the Vilcanota River from the mouth of the Aguas Calientes River. The catchment area of the Am is $\sim 400$ hectares and drains an area lying further north-east of MPP. The last $700 \mathrm{~m}$ of the Am runs in a natural channel cutting through an alluvial plain on the eastern side of MPP. At points where overtopping has occurred in the past

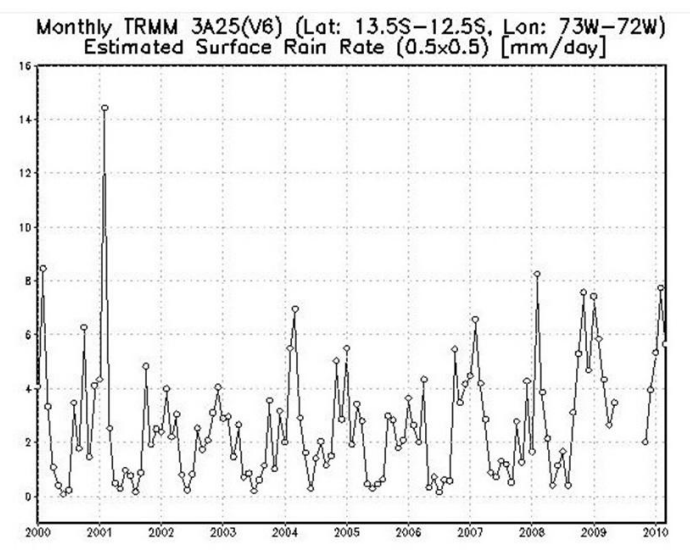

Grabs colu/loes

Ganeratad by NASA'e Giovanni (giovanni.gsto.naea.gov)

Fig. 3. Monthly TRMM $3 \mathrm{~A} 25(\mathrm{~V} 6)$ data over MPP as time series data from January 2000 to March 2010. Data acquired using the GES-DISC Interactive Online Visualization and analysis Infrastructure (Giovanni) as part of the NASA's Goddard Earth Sciences (GES) Data and Information Services Center (DISC).

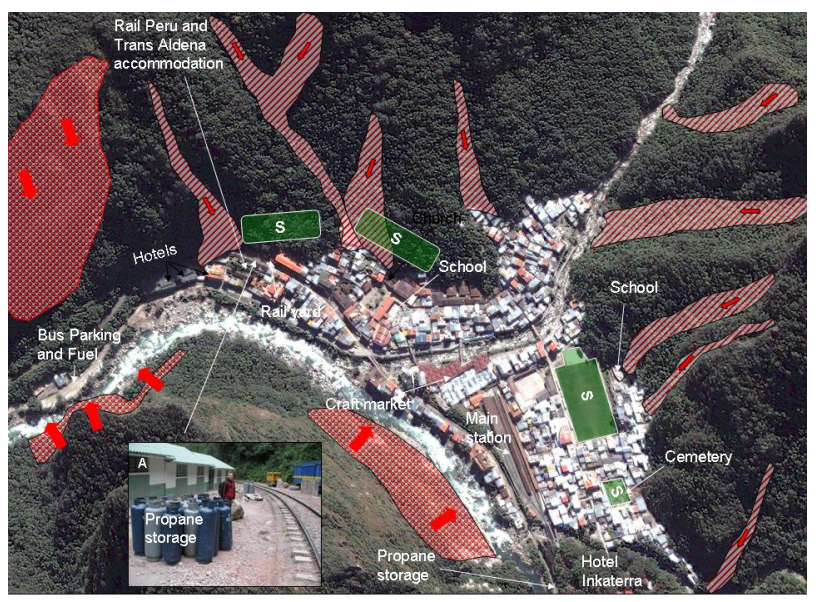

Fig. 4. Quickbird image showing the AC and Am Rivers. Areas prone to rock fall, topples and slides are shown as areas with a red stipple pattern. Drainage lines for floods and debris flows are shown as areas with a red stripped pattern. Designated Safe Areas (S) are shown within green boxes. Inset A shows an area where propane tanks are stored in the open. To the immediate right of the author is a rock that fell into the rail yard in 2007. The explosion and resulting destruction resulting from a ruptured propane tank would be significant.

some portions of the banks have been built up and strengthened by unreinforced stone. The last portion of the channel is severely constricted by a narrow span rail bridge just above its entrance point into the Vilcanota River, to the extent that the Am overtops its channel here on a regular basis in an area adjacent to the passenger rail station and several major hotels (Fig. 6). 


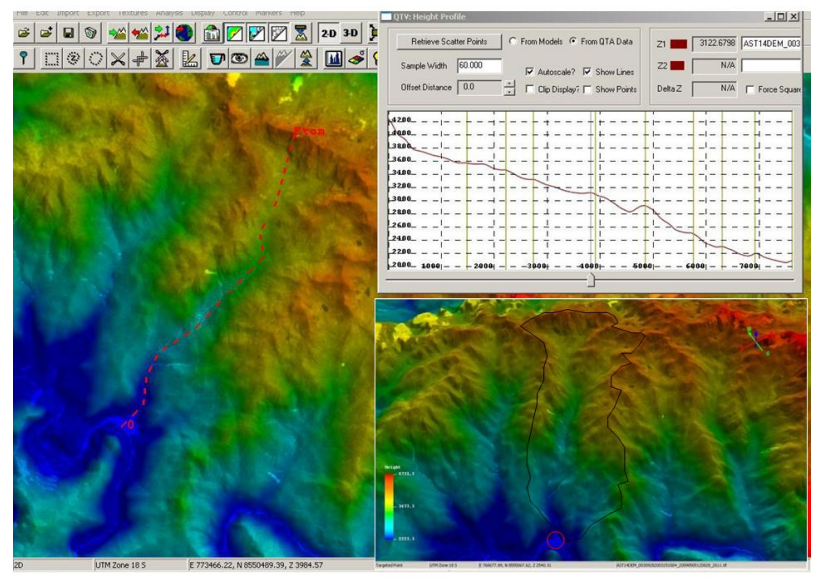

Fig. 5. Colorized DEM and ASTER Band 1 VNIR image used to examine height profile and mensuration data from the head of the Aguas Calientes watershed to MPP. The length of the Aquas Calientes River from the highest point to MPP is calculated to be $7.9 \mathrm{~km}$. The channel profile is shown in the inset top right. Inset lower right shows a perspective view of the colorized DEM and ASTER Band 1 VNIR image. The black polygon shows the outline of the watersheds of the AC and Am which drain to and through MPP (shown in the red circle). Elevation is in meters.

Prior to February 2009, the early warning system in MPP was limited to observation posts located at various points 1 to $2 \mathrm{~km}$ upstream of MPP along the banks of the AC and $\mathrm{Am}$. In practice, these posts were only manned during periods of elevated risk, for example, after a marked reduction in water flow was observed following a period of unusually heavy rain. In such cases, observers were dispatched up river to their posts with instructions to immediately report any unusual sights or sounds either via cell phone or 2-way FM radio. In practice, the GFG team observed that cell phone and 2-way FM radio communication were problematic at many locations along these steep narrow valleys. Furthermore, eyewitnesses reported that "huaycos" could easily attain flow velocities exceeding $10 \mathrm{~m} / \mathrm{s}$ and might easily reach MPP before any response to the observer's warning could be taken. It was also unclear whether changes in flow in the lowest reaches of the AC during periods of intense rain can be reliably correlated with floodwater accumulation several kilometers higher up. The current alert system relies on the skilled judgment of a few individuals, and is prone to degraded performance at night.

\section{System configuration}

The early warning system was to be wholly based on technologies deemed appropriate to the local setting, which in addition to the severe physical environment also included various significant logistical and administrative constraints. From the outset, considerable attention was given to identify-

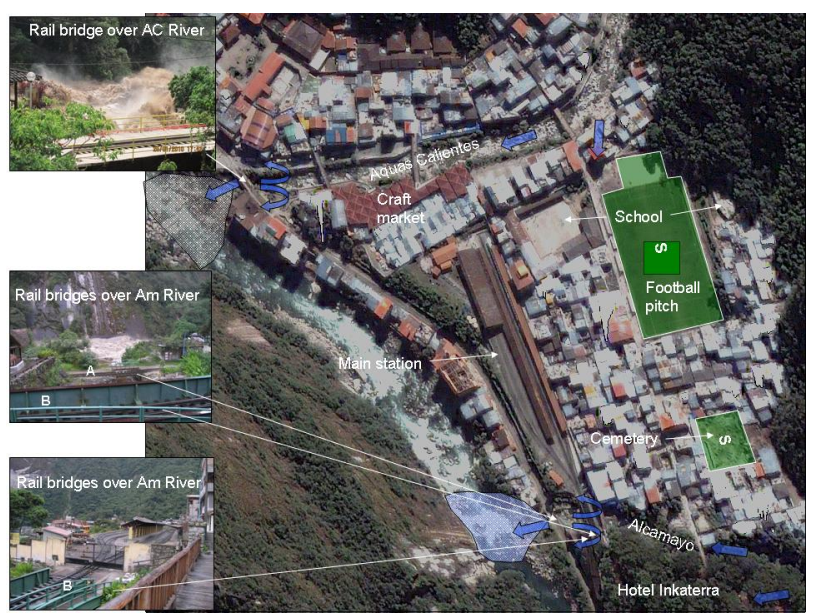

Fig. 6. Quickbird image of MPP showing the AC and Am Rivers. The square blue arrows show areas where the channel changes direction and overtopping has occurred historically. Note that the two "safe" areas shown in green appear to be at risk. Two rail bridges are shown as 1 and 2, upstream of which are curved blue arrows that show where a flow could back-up and overbank.

ing robust power-efficient technologies that could be reasonably expected to survive extended exposures to rain and/or high humidity. The intended purpose of the technology demonstration was to show that it was technically feasible to improve upon the capabilities of the existing municipal early warning system. In particular, the GFG team sought to provide a template for the future development of a hardened permanent system, which could be used by the Civil Defense authorities to monitor weather, river flow, and slope stability along the lower reaches of the AC River, thereby assisting in emergency management decision making. The majority of candidate technologies selected to achieve these aims had never been deployed in similar terrain, at similar altitudes, or in similar climatic conditions. Planning for the installation of these technologies had to be based on coarse-scale knowledge of terrain and urban structure derived mainly from our initial preliminary geohazards assessment in May 2008, from a digital elevation model derived from the 3 arc second SRTM data, and aerial photographs taken in September 2006. Improved geospatial understanding was achieved early in the second site visit and three critical points in the AC river system were identified. These were a steep and narrow rockwalled canyon, the energy dissipation structure (EDS), and the outflow into the Vilcanota River (Fig. 7). Identification of these enabled an informed down-selection of technologies to be made to those that could be effectively deployed at these points under local conditions. Once this was achieved, the expanded aim became to design and to leave in place a working prototype that could monitor the three critical points. 


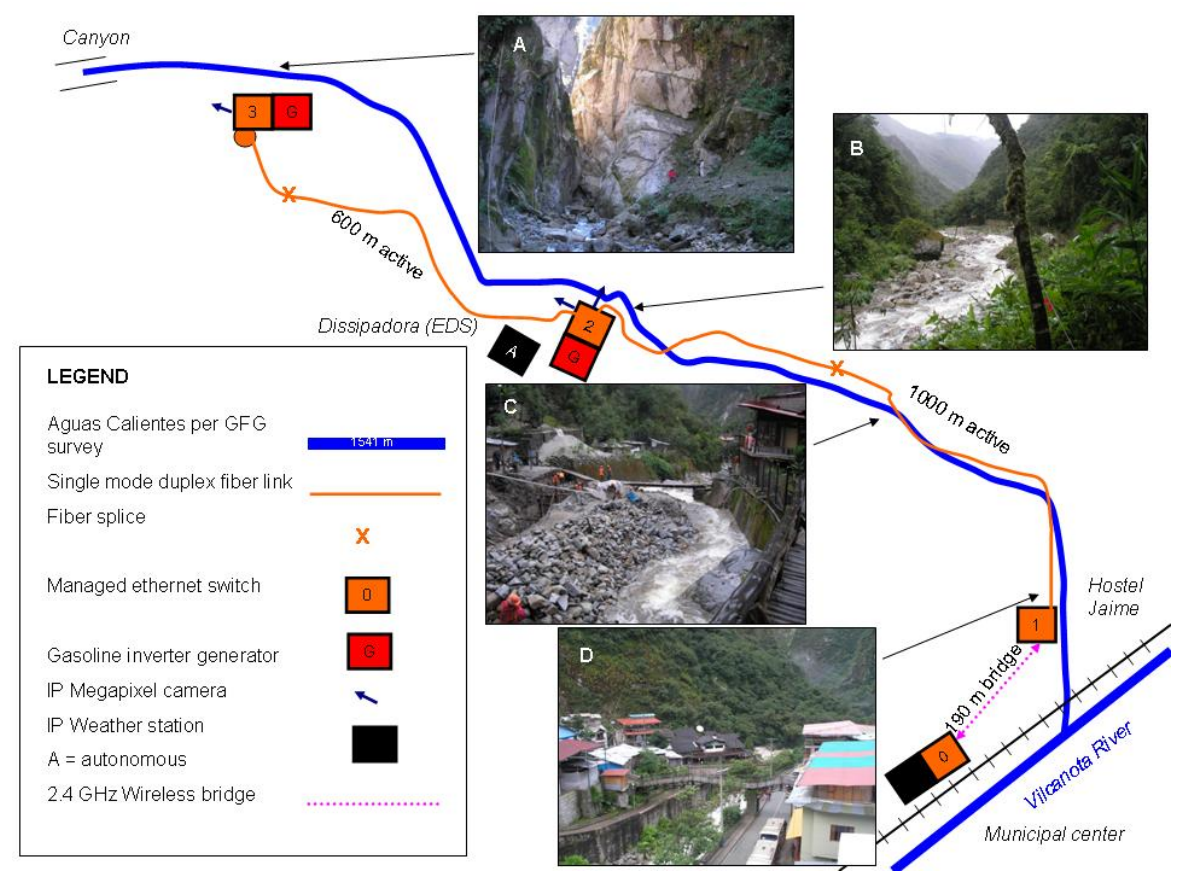

Fig. 7. Simplified plan of the prototype early warning system installed on 6 March 2009 along a $1541 \mathrm{~m}$ section of the Aquas Calientes River. Inset A shows a view upstream to a narrow granite walled canyon. Inset B shows a view downstream to the energy dissipation structure (EDS). Inset $\mathrm{C}$ shows a view on the edge of the engineered channel on the edge of the town. Inset $\mathrm{D}$ from the Hostel Jamie down to the confluence on the Aquas Calientes River with the Vilcanota River.

Candidate technologies from three general categories were evaluated under local conditions. These were communication, sensing, and power which will now be discussed in turn.

\subsection{Communication}

For communication ten candidates were examined. Two sectors of fiber optic cable $(6 \mathrm{~mm}$ OD, 9/125 single mode, duplex, grade $\mathrm{D}, 500 \mathrm{~m}$ with $0.3 \mathrm{~m} \mathrm{ST}$ terminated breakouts) were deployed up and down from the EDS, each was two $500 \mathrm{~m}$ links spliced inside Multilink (Starfighter \#1120-F) boxes. This formed the backbone for a local area network (LAN). Once routes had been cleared in the rainforest and through cluttered urban scape of MPP, the cable was easy to deploy, splice and to check for continuity with laser light. It requires no power. Careful routing and regular inspection was essential since periodic damage was inevitable but manageable. Four Ethernet switches were located, one each at the canyon, EDS, Hotel Jaime and at the Municipal Center (Fig. 7). These provided two-way communication with multiple IP-devices on the LAN. Each switch has eight electrical ports, two optical ports and supports 1 GB per second data rate. Each port requires 2 wires or fibers and supports full duplex. They were easy to deploy but required a clean dry environment and must be protected. Optical transceivers (100BASE-LX/LH SFP) were used to perform electro-optical conversion and were easy to deploy but must be protected. A wireless bridge (Client Bridge-Access Point pair, rated to $1500 \mathrm{~m}$ without an extended antenna, $2.4 \mathrm{GHz}$ Power over Ethernet PoE) was used to test the performance from the Hotel Jaime to the Municipal Center (Figs. 7, 8). This had the advantage of being lower cost than cable in an urban setting. In practice it proved difficult to deploy in MPP due to the need for roof access on private dwellings, power and line of sight (LOS). Once installed it required negligible maintenance but could be disabled by a power failure, spaceuse dispute or loss of LOS due to construction. Computing power was provided by non-ruggedized laptops (Core2Duo, $2.4 \mathrm{GHz}, 3 \mathrm{~GB}, 250 \mathrm{~GB}, 1600 \times 1200)$ that were protected in a waterproof case. These laptops ran surveillance software that allowed for control, management and analysis of multiple video feeds, including motion triggered alarms and pan/tilt/zoom. Cellular phone coverage was available from two Peruvian telecommunications providers but coverage is limited and inconsistent outside MPP in the AC drainage basin. FM commercial radios worked at many locations but were often unavailable, in the wrong place or discharged. Despite its inconsistency it was necessary and useful. At the site of the EDS, an autonomous weather station was installed which had an Iridium modem for up-linking data. In this location, up-link was inconsistent on a fixed hourly schedule. Terrain shadowing was likely responsible and may be overcome either by repeated attempts (if power is available) or by 


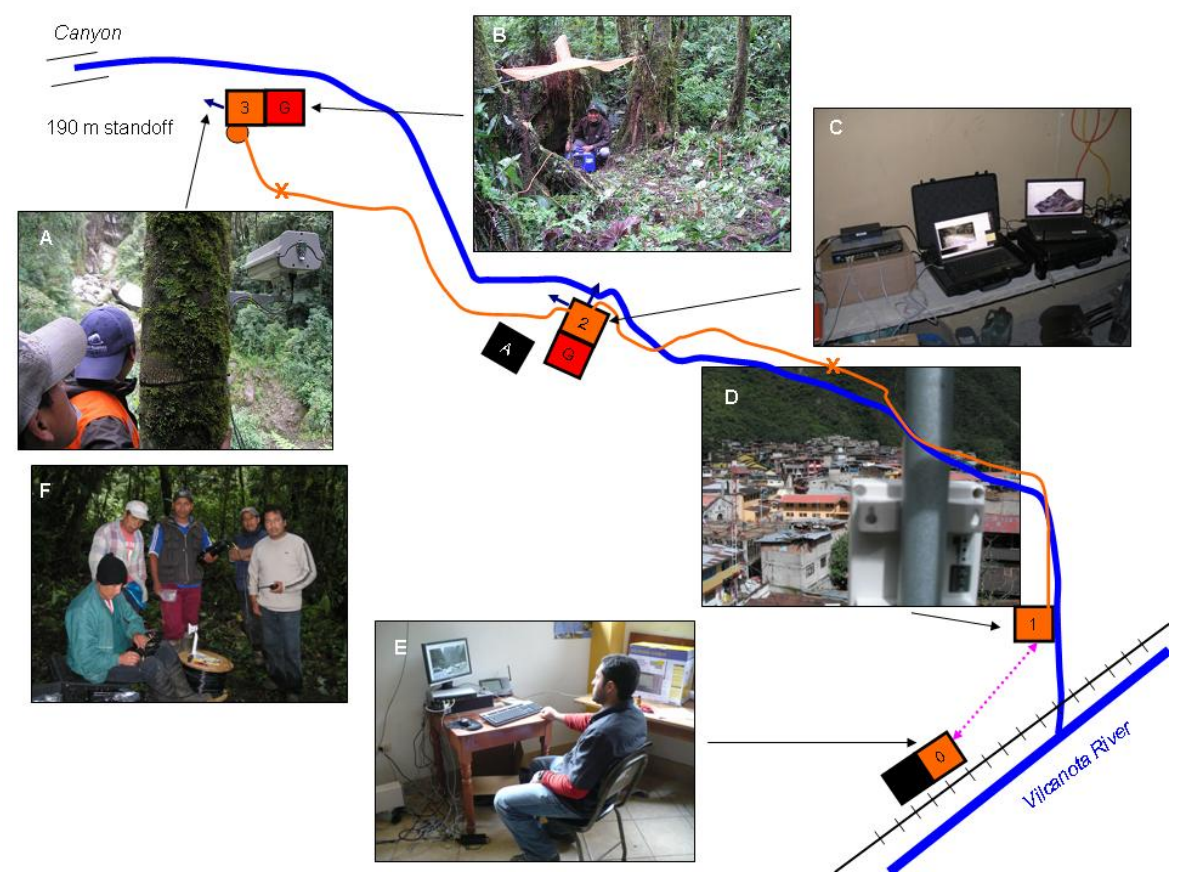

Fig. 8. Communication, Sensors and Power elements in the prototype early warning system. Inset A shows an IP camera mounted up on a tree platform $190 \mathrm{~m}$ stand-off from the narrow granite walled canyon. Inset B shows a portable generator used to power the camera in Inset A. Inset $\mathrm{C}$ shows an Ethernet switch and laptop located at the energy dissipation structure. The image on the screen is the feed from a camera mounted to view the flow level. Inset D shows the wireless bridge at the Hostel Jamie to the Municipal Center. Inset E shows a computer terminal at the Municipal center with an Ethernet switch. The operator is able to view feeds from an IP camera or weather station on the LAN. Inset F shows the team of municipal workers trained to set-up and maintain the equipment in the prototype warning system.

coordinating attempts with scheduled satellite passes. The optimal site for our configuration of autonomous weather stations is higher up the watershed in the headwaters. Positional information was recorded using hand-held Global Positioning System for reference to other geospatial data. When compared with georeferenced ASTER images, GPS locations were found to be poor, likely due to constraints on visible sky coverage at ground level in steep terrain with overhead rainforest canopy. At present Peru has no signal correction similar to the Wide Area Augmentation System (WAAS) available in North America.

\subsection{Sensors}

For sensors, eight technologies were tested. Three IP-video camera types were installed that we designated as: utility (1.3 Mega Pixel (MPx) D/N IP Camera, with internal infrared LED illuminator ring, 3.3-12 mm lens, PoE), premium (5 MPx D/N IP Camera, with mechanical filter, 4-10 mm lens, PoE), and precision (3 MPx IP Camera, motorized 8-48 mm lens, and does not support PoE). The IP-video utility camera provides potential for night vision at reasonable cost but in cold wet night-time weather, the transparent viewport developed a ring of localized fogging. This was resolved by mounting them in a larger heated and ventilated enclosure
(Fig. 8) but night vision was degraded. These cameras do not work in "total" darkness but can monitor illuminated fiducials (Bulmer et al., 2007, 2009) within an otherwise dark scene. The IP-video premium camera was three times the cost of the IP-video utility camera and produced a picture quality that was visibly superior. In low light, the daylight filter retracts increasing the gain and the ability to view in faint moonlight without supplemental IR. It needed to be mounted in a heated enclosure. The IP-video precision camera was four times the cost of the utility camera, daytime vision only but permitted longer stand-offs (out to $>2000 \mathrm{~m}$ ). This was best suited for installation on a robotic base in a built structure, with panoramic windows that then enable sequential monitoring of many slopes. Video was fed to the Municipality and to portable laptops (Fig. 8). Two different weather station technologies were demonstrated (Fig. 7). The first was a commercial unit installed at the Municipal Center with a well proven record. This had sensors that measured barometric pressure, relative humidity, temperature, dew point, wind direction and speed, rainfall, time and included a solar radiation shield. Power options were solar/battery/PoE. Connection was established via wireless $(900 \mathrm{MHz})$, Ethernet cable (LAN) to a computer and the Internet. For deployment up in the AC basin, the second weather station technology was custom designed and built to be autonomous, portable, 
rugged, weather resistant and stand alone. This station contained a rain gauge tipping bucket, a barometric pressure sensor, wind sensor prop vane, multiple-plate free-standing radiation shield enclosing a temperature and relative humidity sensor, solar regulator, datalogger, Iridium short burst modem with external antenna, and a sealed 25 Amp-hr $12 \mathrm{v}$ lead-acid battery. The electronics and battery were contained in a hardened plastic case with weather resistant connections of the feedthroughs for cables from external sensors. This was set-up at several locations around the EDS. All sensors were made operational and data stored in the datalogger was successfully retrieved using direct connection to a laptop and via uplink over the Iridium satellite network with data served over the internet to a dedicated web site.

\subsection{Power}

For power, seven candidates were examined. Upriver of MPP on the Vilcanota River, is a hydroelectric plant that supplied electricity to the town. Residents reported regular power outages. No power infrastructure extends up the $\mathrm{AC}$ drainage basin to the EDS though the potential exists for installing 5 to $10 \mathrm{~kW}$ pico-hydro stations. Two gasoline generators (Inverter Generator, $120 \mathrm{VAC}, 12 \mathrm{DC}$, rated $900 \mathrm{~W}$, standard 2.5 liter tank provided power for $14 \mathrm{~h}$ ) were used outside MPP to provide power to the prototype warning system (Fig. 8). These used $\sim 4$ liters per day, required weekly oil changes and minimal maintenance over a life of $\sim 1000 \mathrm{~h}$. Methanol fuel cells and diesel generators were determined to be impractical due to altitude, special fuel needs, cost and weight. Various types of solar photovoltaics were deployed and tested but it was found that that there was insufficient light (hours $\times$ intensity) at all locations of interest. Powerover-Ethernet was provided through the design of the Ethernet switches selected and ran to all 8 ports per switch allowing IP-devices to be powered through RJ-45 communication cable. This eliminated the need for transformers and separate power cables. Switch mode power supplies were required for all switches, IP-sensors, computers, the wireless bridge and robotic base that were plugged into power outlets in MPP and the portable diesel generators. These proved extremely cost effective and avoided concern about power quality and voltage.

\section{Improved hazard warning}

The primary objective of the technology demonstration was to show that geohazard risk can be monitored continuously along the AC River. A set of suitable technology was configured as a working prototype with a modular design that was initially able to collect data as much as $2000 \mathrm{~m}$ up-river from the Municipal Center. This was demonstrated and conveyed to the community on 6 March 2009, and a local team (Fig. 8) continued to operate it on an intermittent basis until mid-

\section{Operating Environment}

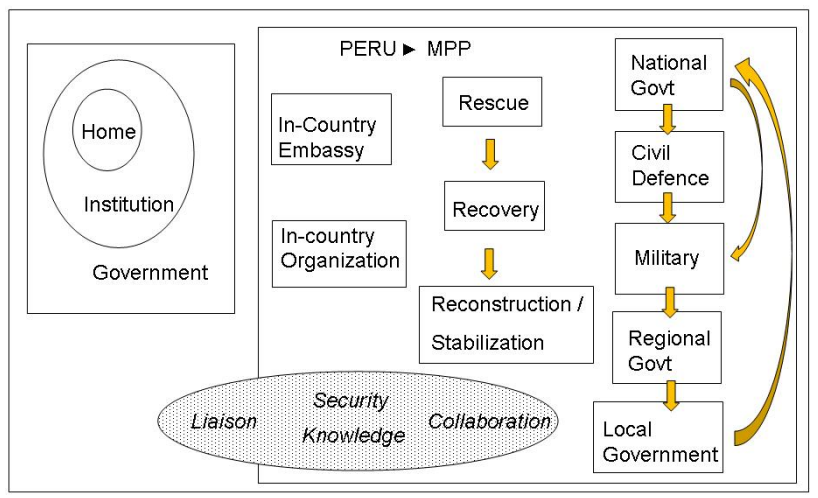

Fig. 9. A schematic representation of the operating space of the GFG in working on the Machu Picchu project.

June. The secondary objective was to survey the AC River and its adjacent slopes, with sufficient accuracy to determine lines-of-sight and to model channel carrying capacity. In practice, the range of useful coverage begins at the AC's confluence with the Vilcanota and ends at the Canyon. This project proved the basic feasibility of technology-based hazard monitoring under local conditions (Farquhar and Bulmer, 2009). Many lessons have been identified which provide a set of concise guidelines that define a recommended approach to further development of a permanent warning system in MPP.

\section{Measures of effectiveness and operating space}

The GFG became involved with MPP after it was approached by the World Bank to provide expert advice and recommendations on geohazards. Over the two-year duration of the project, the GFG conducted detailed site investigations in MPP and delivered technical written reports and oral presentations on the geohazards and prototype warning system to primary and secondary stakeholders. Despite highlighting high risk and poor preparedness, the February 2010 flood demonstrated that few, if any, of the project recommendations had been implemented. This raises questions as to how to measure the effectiveness of the work undertaken by the GFG. From the perspective of the expert user, the effectiveness of the work is evident from the findings of the geohazard assessment and the successful operation of the prototype warning system. Interactions between the GFG and expert stakeholders were constructive and the significance of the work was understood and valued. Whereas the same appeared to be true of the interactions with non expert stakeholders, events surrounding the February 2010 flood revealed that this was not the case. In fact, no written reports, oral presentations or practical demonstrations given by the GFG appeared to influence the actions of non experts, even in the 
context of an extended period of unusually heavy rain preceding the flood. The effectiveness of the work of the GFG on non experts therefore appears to have been negligible. This is distressing and highlights the need for the interface with the non expert community to be considered at every stage in the development of any geohazard assessment and warning system. In the context of the work of the GFG in Peru, this need was identified early and significant effort was devoted to understanding the operating environment (Fig. 8) which is complex due to the decentralized nature of government. The GFG attended meetings with expert and non expert stakeholders at the international, national, provincial and local levels. Ultimately, events revealed that despite the remits of expert organizations, non experts were and are the key decision makers. They have the findings of the GFG but have chosen to-date not to act upon them. Achieving success with non experts will likely require long term engagement and that is beyond the remit given to the GFG by the World Bank.

Acknowledgements. Financial support for this project was provided by the University of Maryland Baltimore County and The World Bank, and valuable technical services were graciously donated by Najib Roshan. In addition, GFG wishes to acknowledge the invaluable assistance of JCET and Mechanical Engineering staff at UMBC, MINCETUR and COPESCO, PeruRail, the Hotel Inkaterra, the Alcalde and Municipal Government of Machu Picchu Pueblo, and many individual stakeholders. Of these, Sr. Jaime Cordoba deserves special recognition for a selfless contribution to increased community security. The authors would also like to thank Masud Roshan, David Finnegan and CRREL, and Margarita Pajaro.

Edited by: T. Glade

Reviewed by: H. Paulsen and another anonymous referee

\section{References}

Marocco, R.: Geologie des Andes Peruviennes: Un segment W. E. de la chaine des Andes Peruviennes; la deflexion D'Abancy-Etude geologique de la Cordillere Orientale et des hauts plateaux entre Cusco et San Miguel, $\mathrm{PhD}$ thesis, Academie de Montpellier, Universite des Sciences et Techniques de Languedoc, Montpellier, France, 1977.

Bulmer, M. H., Farquhar, T., Roshan, M, Akhtar, S. S., and Wahla, S. K.: Landslide Hazards After the 2005 Kashmir Earthquake, EOS, Transactions, American Geophysical Union, 88(5), 53-55, 2007.

Bulmer, M. H., Farquhar, T., and Roshan, M.: Effective use of Fiducial-based photogrammetry for tracking large scale outdoor motion, J. Exp. Eng.Techs., 34(1), 40-47, doi:10.1111/j.17471567.2008.00474, 2008.

Bulmer, M. H. and Farquhar, T.: First Report Peru: Vilcanota Valley Slope Monitoring for Flash Flood Prevention. May 2008. Geophysical Flow Observatory/ Landslide Mitigation Group Confidential Report to the World Bank, GFLO 08-05.1, 27 pp., 2008.

Farquhar, T. and Bulmer, M. H.: Second Report Peru: Vilcanota Valley Slope Monitoring for Flash Floods and Other Natural Hazards. Geophysical Flow Observatory/Landslide Mitigation Group. Confidential Report to the World Bank. GFLO\#09.20MPP, 54 pp., 2009. 